Article

\title{
In Vitro Weight Loss of Dental Composite Resins and Glass-Ionomer Cements Exposed to a Challenge Simulating the Oral Intake of Acidic Drinks and Foods
}

\author{
Marco Colombo $^{1}(\mathbb{D})$, Simone Gallo ${ }^{1, *(\mathbb{D}}$, Marco Chiesa ${ }^{1}$, Claudio Poggio $^{1}\left(\mathbb{D}\right.$, Andrea Scribante ${ }^{1, *(\mathbb{D})}$, \\ Paolo Zampetti ${ }^{1}$ and Giampiero Pietrocola ${ }^{2}$ (D)
}

1 Department of Clinical-Surgical, Diagnostic and Pediatric Sciences-Section of Dentistry, University of Pavia, 27100 Pavia, Italy; marco.colombo@unipv.it (M.C.); marco.chiesa@unipv.it (M.C.);

claudio.poggio@unipv.it (C.P.); paolo.zampetti@unipv.it (P.Z.)

2 Department of Molecular Medicine, Unit of Biochemistry, University of Pavia, 27100 Pavia, Italy; giampiero.pietrocola@unipv.it

* Correspondence: simone.gallo02@universitadipavia.it (S.G.); andrea.scribante@unipv.it (A.S.)

\section{check for}

updates

Citation: Colombo, M.; Gallo, S.; Chiesa, M.; Poggio, C.; Scribante, A.; Zampetti, P.; Pietrocola, G. In Vitro Weight Loss of Dental Composite Resins and Glass-Ionomer Cements Exposed to a Challenge Simulating the Oral Intake of Acidic Drinks and Foods. J. Compos. Sci. 2021, 5, 298. https://doi.org/10.3390/jcs5110298

Academic Editor:

Francesco Tornabene

Received: 9 September 2021

Accepted: 9 November 2021

Published: 13 November 2021

Publisher's Note: MDPI stays neutral with regard to jurisdictional claims in published maps and institutional affiliations.

Copyright: (c) 2021 by the authors. Licensee MDPI, Basel, Switzerland. This article is an open access article distributed under the terms and conditions of the Creative Commons Attribution (CC BY) license (https:// creativecommons.org/licenses/by/ $4.0 /)$.

\begin{abstract}
Specific conditions of the oral cavity, such as intake of acidic drinks, foods, and drugs, represent a damage both for teeth as well as restorative materials. The aim of this in vitro study is to assess the influence of an acidic challenge on the weight loss of biomimetic restorative dental materials (composite resins and glass-ionomer cements, respectively). Seven products recently available in the marked have been tested in this study for the two kinds of materials, respectively. Resin composites were divided into Groups 1A-7A, whereas glass-ionomer cements into Groups 1B-7B. A total of six samples was considered for each group, among which two were stored into distilled water (control samples) whereas the other four were immersed into soft drink (Coca-Cola, Coca-Cola Company, Milano, Italy) for 7 days. Respectively, after 1, 3 and 7 days, weight was assessed for each sample and the percentage weight loss was calculated. For all the composite resins (Groups 1A-7A), no significant intergroup or intragroup differences occurred for the weight loss values $(p>0.05)$. Conversely, all glass-ionomers (Groups 1B-7B) showed a significant and progressive weight loss after 1,3 , and 7 days of acid challenge $(p<0.05)$ (intragroup differences). This reduction was significantly lower in case of GC Equia Forte + Coat and ChemFil Rock, with respect to the other cements $(p<0.05)$ (intergroup differences). In conclusions, all the biomimetic composite resins showed a reliable behavior when exposed to acidic erosion, whereas glass-ionomers cements generally tended to solubilize. However, the additional use of a protective layer above these latter materials could reduce this event. Despite these results appear to be interesting from a clinical point of view, future morphological evaluations should be conducted to evaluate the superficial changes of the materials after acidic explosion.
\end{abstract}

Keywords: dentistry; conservative; restorative; resin composites; glass-ionomer cements; acid exposure; acidic drinks

\section{Introduction}

Along with periodontal disease, dental caries is one of the most frequent oral pathologies which represents the major cause of tooth loss [1]. This process corresponds to an infection of the hard surface of the tooth which leads to the dissolution of its mineral component, hydroxyapatite [2]. With the aim of restoring both the function as well as the aesthetic of compromised teeth, direct restorations by means of dental biomaterials are one of the main therapeutic options [3]. A wide range of materials by different manufacturers have been proposed for this treatment, in particular composite resins and glass-ionomers [4]. Specifically, the formers allow to carry out permanent dental restorations, with good aesthetic and adequate mechanical/chemical characteristics; conversely, glass-ionomers are 
more frequently used for temporary restorations, besides a frequent use in orthodontics and pedodontics [3]. The good clinical performance of restorations is one of the main focuses which clinicians should achieve. However, despite their initial intrinsic properties, several conditions are recognized to compromise materials' stability, including intrinsic (e.g., eating disorders) and extrinsic factors (e.g., acidic diet, intake of acidic drugs, and unproper oral hygiene), besides the normal wear consequent to the exposition in the oral cavity [5-8]. Accordingly, functional stability of restorative materials should be periodically controlled to replace them when necessary.

Based on these considerations, several research studies have been conducted to assess the change of restorative materials exposed to artificial saliva mimicking normal oral conditions. These studies generally show a surface decrease of microhardness as well as an increase of roughness [3]. However, the abovementioned storage medium does not properly mimic more challenging situations, like the case of high intake of acidic drinks or foods. Accordingly, many other Authors have focused on the action of acid storages on restorative dental materials. In fact, the intake of acid substances with the diet is increasing with a high risk of dental wear, biomaterials' degradation, and risk of restoration failure $[9,10]$.

The aim of the present study is to evaluate and compare the action of acidic challenges on the weight loss of biomimetic restorative materials from different manufacturers, including resin composites and glass ionomers. The two null hypotheses of the study are that no intergroup and intragroup significant differences occur considering the weight loss after acidic expositions of the resin composites and glass ionomers tested.

\section{Materials and Methods}

\subsection{Materials Tested}

Seven different resin composites and glass ionomers have been, respectively, considered in this study and subdivided into groups. The list of the materials tested, their specific compositions, and the relative manufacturers are shown in Tables 1 and 2.

Table 1. Composite resins tested in this study.

\begin{tabular}{|c|c|c|c|c|c|c|}
\hline Group & Material & Type & Composition & $\begin{array}{c}\text { Filler } \\
\text { Content \% } \\
(w / w)\end{array}$ & Manufacturer & Lot \# \\
\hline $1 \mathrm{~A}$ & $\begin{array}{l}\text { ENAMEL } \\
\text { Plus HRi } \\
\text { Bio } \\
\text { Function }\end{array}$ & $\begin{array}{l}\text { Microfilled } \\
\text { hybrid } \\
\text { composite }\end{array}$ & $\begin{array}{l}\text { Matrix: urethane dimethacrylate } \\
\text { (UDMA), tricyclodecane dimethanol } \\
\text { dimethacrylate(TCDDA), no comonomers } \\
\text { and no Bis-GMA Filler: glass filler, high } \\
\text { dispersion silicon dioxide, fluorine }\end{array}$ & $74(w / w)$ & $\begin{array}{l}\text { Micerium } \\
\text { S.p.A., } \\
\text { Avegno, } \\
\text { Italy }\end{array}$ & 2018006379 \\
\hline $2 \mathrm{~A}$ & Essentia & $\begin{array}{l}\text { Microfilled } \\
\text { hybrid } \\
\text { composite }\end{array}$ & $\begin{array}{c}\text { Matrix: urethane dimethacrylate } \\
\text { (UDMA), Bis-MEPP, Bis-EMA, Bis-GMA, } \\
\text { TEGDMA Filler: prepolymerised fillers, } \\
\text { barium glass, fumed silica }\end{array}$ & $81(w / w)$ & $\begin{array}{l}\text { GC Corpo- } \\
\text { ration, } \\
\text { Tokyo, } \\
\text { Japan }\end{array}$ & 151109C \\
\hline $3 \mathrm{~A}$ & $\begin{array}{l}\text { Filtek } \\
\text { Supreme } \\
\text { XTE }\end{array}$ & $\begin{array}{l}\text { Nanofilled } \\
\text { composite }\end{array}$ & $\begin{array}{c}\text { Matrix: Bis-phenol A } \\
\text { diglycidylmethacrylate (Bis-GMA), } \\
\text { triehtylene glycol dimethacrylate } \\
\text { (TEGDMA), urethane dimethacrylate } \\
\text { (UDMA), bis-phenol A polyethylene } \\
\text { glycol diether dimethacylate Filler: silica } \\
\text { nanofillers (5-75 nm), zirconia/silica } \\
\text { nanoclusters }(0.6-1.4 \mu \mathrm{m})\end{array}$ & $78.5(w / w)$ & $\begin{array}{l}\text { 3M ESPE, } \\
\text { St. Paul, } \\
\text { MN, USA }\end{array}$ & N748173 \\
\hline $4 \mathrm{~A}$ & $\begin{array}{l}\text { ENAMEL } \\
\text { Plus HRi } \\
\text { Flow }\end{array}$ & $\begin{array}{l}\text { Microfilled } \\
\text { hybrid } \\
\text { composite }\end{array}$ & $\begin{array}{l}\text { Matrix: urethane dimethacrylate } \\
\text { (UDMA), Butanedioldimethacrylate } \\
\text { Diurethandimethacrylate, Filler: glass } \\
\text { filler, high dispersion silicon dioxide }\end{array}$ & $53(w / w)$ & $\begin{array}{l}\text { Micerium } \\
\text { S.p.A., } \\
\text { Avegno, } \\
\text { Italy }\end{array}$ & 2017008768 \\
\hline
\end{tabular}


Table 1. Cont.

\begin{tabular}{|c|c|c|c|c|c|c|}
\hline Group & Material & Type & Composition & $\begin{array}{c}\text { Filler } \\
\text { Content } \% \\
(w / w)\end{array}$ & Manufacturer & Lot \# \\
\hline $5 \mathrm{~A}$ & SDR Flow & $\begin{array}{l}\text { Microfilled } \\
\text { hybrid } \\
\text { composite }\end{array}$ & $\begin{array}{l}\text { Matrix: modified UDMA, EBPADMA, } \\
\text { TEGDMA Filler: barium and strontium } \\
\text { alumino-fluoro-borosilicate glasses }\end{array}$ & $47.3(w / w)$ & $\begin{array}{c}\text { Dentsply } \\
\text { Sirona, } \\
\text { Ballantyne } \\
\text { Corporate Pl, } \\
\text { Charlotte, } \\
\text { USA }\end{array}$ & 2003000392 \\
\hline $6 \mathrm{~A}$ & $\begin{array}{l}\text { Ceram.X } \\
\text { Universal }\end{array}$ & $\begin{array}{l}\text { Nanoceramic } \\
\text { composite }\end{array}$ & $\begin{array}{l}\text { Matrix: methacrylate modified } \\
\text { ploysiloxane, dimethacylate resin, } \\
\text { ethyl-4(dimethylamino) benzoate, iron } \\
\text { oxide pigments, titanium oxide pigments, } \\
\text { aluminum sulfo silicate pigments Filler: } \\
\text { barium-aluminum-borosilicate glass } \\
(1.1-1.5 \mu \mathrm{m}), \text { methacrylate functionalized } \\
\text { silicon dioxide nano filler }(10 \mathrm{~nm})\end{array}$ & $76(w / w)$ & $\begin{array}{c}\text { Dentsply } \\
\text { Sirona, } \\
\text { Ballantyne } \\
\text { Corporate Pl, } \\
\text { Charlotte, } \\
\text { USA }\end{array}$ & 1507000661 \\
\hline $7 \mathrm{~A}$ & $\begin{array}{c}\text { Gradia } \\
\text { direct Flow }\end{array}$ & $\begin{array}{l}\text { Microfilled } \\
\text { hybrid } \\
\text { composite }\end{array}$ & $\begin{array}{c}\text { Matrix: urethanedimethacrylate (UDMA), } \\
\text { dimethacrylate camphorquinone Filler: } \\
\text { fluoro-alumino-silicate glass silica } \\
\text { powder }\end{array}$ & $67(w / w)$ & $\begin{array}{l}\text { GC } \\
\text { Corporation, } \\
\text { Tokyo, Japan }\end{array}$ & $140606 \mathrm{~A}$ \\
\hline
\end{tabular}

Table 2. Glass-ionomers tested in this study.

\begin{tabular}{|c|c|c|c|c|}
\hline Group & Material & Composition & Manufacturer & Lot \# \\
\hline $1 \mathrm{~B}$ & Voco IonoStar Plus & $\begin{array}{c}\text { Powder: fluoro-alumino-silicate glass, polyacrylic } \\
\text { acid, tartaric acid } \\
\text { Liquid: polyacrylic acid solution }\end{array}$ & $\begin{array}{l}\text { Voco GmbH, } \\
\text { Cuxhaven, } \\
\text { Germany }\end{array}$ & 1620354 \\
\hline $2 \mathrm{~B}$ & $\begin{array}{l}\text { Voco IonoStar Plus } \\
\quad+\text { Easy Glaze }\end{array}$ & $\begin{array}{l}\text { Powder: fluoro-alumino-silicate glass, polyacrylic } \\
\text { acid, tartaric acid Liquid: polyacrylic acid } \\
\text { solution Light Curing Protective Coating }\end{array}$ & $\begin{array}{l}\text { Voco GmbH, } \\
\text { Cuxhaven, } \\
\text { Germany }\end{array}$ & $\begin{array}{l}1620354 \text { Easy } \\
\text { Glaze } 1411097\end{array}$ \\
\hline 3B & GC Equia Forte & $\begin{array}{l}\text { Powder: fluoro-alumino-silicate glass, polyacrylic } \\
\text { acid powder, pigment Liquid: polyacrylic acid, } \\
\text { distilled water, polybasic carboxylic acid }\end{array}$ & $\begin{array}{l}\text { GC Corporation, } \\
\text { Tokyo, Japan }\end{array}$ & $161020 \mathrm{~A}$ \\
\hline $4 \mathrm{~B}$ & $\begin{array}{l}\text { GC Equia Forte + } \\
\text { Coat }\end{array}$ & $\begin{array}{c}\text { Powder: fluoro-alumino-silicate glass, polyacrylic } \\
\text { acid powder, pigment Liquid: polyacrylic acid, } \\
\text { distilled water, polybasic carboxylic acid Light } \\
\text { Curing Protective Coating }\end{array}$ & $\begin{array}{l}\text { GC Corporation, } \\
\text { Tokyo, Japan }\end{array}$ & $\begin{array}{l}\text { 161020A Coat } \\
1605131\end{array}$ \\
\hline $5 B$ & $\begin{array}{l}\text { 3M ESPE Ketac } \\
\text { Universal Aplicap }\end{array}$ & $\begin{array}{l}\text { Powder: Al-Ca-La fluorosilicate glass, copolymer } \\
\text { acid (acrylic and maleic acid) Liquid: } \\
\text { polyalkenoic acid, tartaric acid, water }\end{array}$ & $\begin{array}{l}\text { 3M ESPE, St Paul, } \\
\text { MN, USA }\end{array}$ & 634330 \\
\hline $6 \mathrm{~B}$ & $\begin{array}{l}\text { GC Fuji TRIAGE } \\
\text { CAPSULE }\end{array}$ & $\begin{array}{l}\text { Powder: fluoro-alumino-silicate glass Liquid: } \\
\text { polyacrylic acid, distilled water }\end{array}$ & $\begin{array}{l}\text { GC Corporation, } \\
\text { Tokyo, Japan }\end{array}$ & 1611011 \\
\hline $7 \mathrm{~B}$ & ChemFil Rock & $\begin{array}{l}\text { Powder: zinc-modified fluoro alumino silicate } \\
\text { glass Liquid: polyacrylic and itaconic acid }\end{array}$ & $\begin{array}{l}\text { Dentsply Sirona, } \\
\text { Ballantyne } \\
\text { Corporate Pl, } \\
\text { Charlotte, USA }\end{array}$ & 1607000503 \\
\hline
\end{tabular}

\subsection{Sample Size Calculation}

Sample size calculation (alpha $=0.05$; power $=80 \%$ ) was performed considering a continuous variable. Concerning the primary outcome ( $\%$ of weight loss), an expected mean of 1.75 was hypothesized, with a standard deviation of 0.85 [11]. The expected difference between the means was supposed to be 1.35, and therefore 6 specimens were requested for each group. 


\subsection{Samples' Preparation}

\subsubsection{Composite Resins}

Each sample of the materials tested was inserted into silicon rings (height $2 \mathrm{~mm}$, internal diameter $6 \mathrm{~mm}$, and external diameter $8 \mathrm{~mm}$ ) to obtain equal specimens. Molds were positioned above a dark opaque paper background with a polyester matrix strip interposed, to obtain a smooth surface under the material, as well as to avoid light reflection from the bottom thus reducing artificial hardening of this area. For each product, the A2 Vita shade has been chosen to avoid the effects of colorants on light-curing [12].

Each mold has been slightly overfilled and a second polyester matrix strip (Mylar strip, Henry Schein, Melville, NY, USA) was positioned on the top to avoid oxygen interfering with the polymerization of the most superficial layer of the composite [13]; to extrude the excess composite resin and obtain a flat surface, a glass slide was pressed against the upper polyester film and removed before curing [14].

Each sample was light-cured for $40 \mathrm{~s}$ with the LED unit Celalux 2 (Voco, Cuxhaven, Germany), and then removed from the mold without conducting polishing. Before every use, the cordless curing unit was maintained at full charge, and irradiance was checked with a radiometer (SDS Kerr, Orange, CA, USA). The distal end of the light guide was placed perpendicular to the surface of the matrix strip, and positioned concentrically with the mold, before starting the light-curing of the samples, which only took place on their external (top) side. Exclusively one light polymerization mode was used, with an output irradiance of $1000 \mathrm{~mW} / \mathrm{cm}^{2}$ [12].

All the samples were subsequently weighed with a Mettler-Toledo precision balance (AE1633, Mettler-Toledo SPA, Novate Milanese, Milan, Italy) with metering accuracy of $0.01 \mathrm{mg}$. Subsequently, for each composite resin, specimens were immersed in $50 \mathrm{~mL}$ of a soft drink (Coca-Cola Classic, Coca-Cola Company, Milano, Italy) (acidifying agent: phosphoric acid; measured $\mathrm{pH}$ value: 2.4$)$ at room temperature $\left(18 \pm 1{ }^{\circ} \mathrm{C}\right)$

After $24 \mathrm{~h}$, each specimen was removed from the liquid using tweezers, then dried with blotting paper, left undisturbed for $60 \mathrm{~min}$ to completely dry, weighed with the precision balance as previously described, and then immersed again in the storage medium. This procedure was subsequently repeated after 3 and 7 days since the first immersion.

\subsubsection{Glass-Ionomer Cements}

Following the same procedure previously described for resin composites, each sample of the materials tested was inserted into silicon rings (height $2 \mathrm{~mm}$, internal diameter $6 \mathrm{~mm}$, and external diameter $8 \mathrm{~mm}$ ) to obtain equal specimens. Before this step, glass-ionomer cements have been vibrated according to the indications of every single manufacturer. All the samples were then weighed with the same precision balance used for the resin composites.

Subsequently, for each glass-ionomer cement, specimens were immersed in $50 \mathrm{~mL}$ of a soft drink (Coca-Cola Classic, Coca-Cola Company, Milano, Italy) (acidifying agent: phosphoric acid; measured $\mathrm{pH}$ value: 2.4$)$ at room temperature $\left(18 \pm 1^{\circ} \mathrm{C}\right)$. The subsequent procedures were the same as described for composite resins in Section 2.3.1.

\subsection{Statistical Analysis}

Data have been subjected to analysis of variance (One-way ANOVA) followed by Bonferroni's post hoc tests. Analyses were performed using Prism 4.0 (GraphPad Software, San Diego, CA, USA). Two-tailed $p$ values of 0.05 were considered statistically significant.

\section{Results}

\subsection{Composite Resins}

As shown in Table 3 and in Figure 1, the exposure to the acidic drink of all composite resins tested has caused no significant weight loss after 1,3, and 7 days. No significant intergroup or intragroup differences have been assessed $(p>0.05)$. 
Table 3. Weight loss of composite resins after 1, 3, and 7 day of acid challenge: data are expressed as medium percentage of weight loss.

\begin{tabular}{cccc}
\hline GROUPS & \multicolumn{3}{c}{ WEIGHT LOSS (\%) } \\
\cline { 2 - 4 } & 1 Day & 3 Days & 7 Days \\
\hline 1A. ENAMEL Plus HRi Bio Function & 0.61 & 0.62 & 0.67 \\
\hline 2A. Essentia & 0.76 & 0.78 & 0.81 \\
\hline 3A. FILTEK Supreme XTE & 0.86 & 1.20 & 0.39 \\
\hline 4A. ENAMEL Plus HRi Flow & 0.35 & 0.36 & 0.5 \\
\hline 5A. SDR Flow & 0.02 & 0.02 & 1.30 \\
\hline 7A. Gradia direct Flow & 1.08 & 1.12 & 0.07 \\
\hline
\end{tabular}

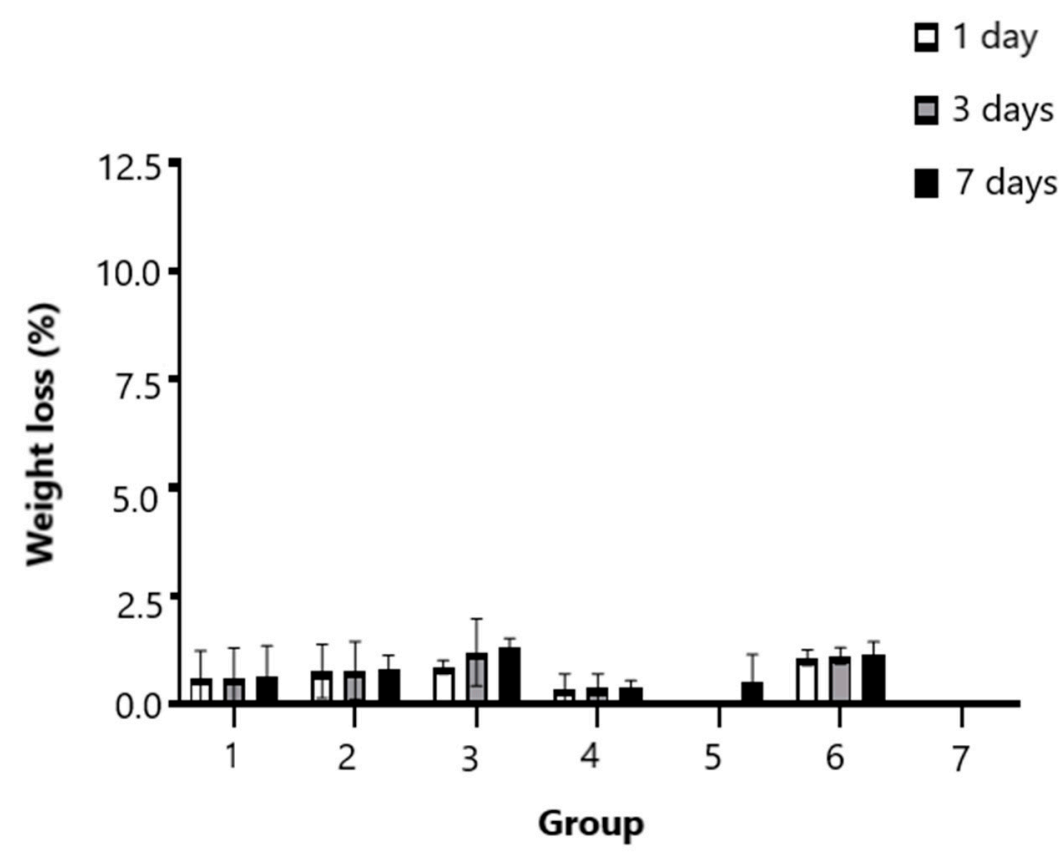

Figure 1. Composite resins: representation of weight loss after acid challenges.

\subsection{Glass-Ionomer Cements}

As shown in Table 4 and in Figure 2, the exposure to the acidic drink of all glass ionomer cements tested has caused significant and progressive weight losses after 1, 3, and 7 days (intergroup differences) $(p<0.05)$. As regards intragroup differences, group $4 \mathrm{~B}$ and $7 \mathrm{~B}$ reported the lowest weight loss with respect to the other groups $(p<0.05)$.

Table 4. Weight loss of glass-ionomer cements after 1, 3, and 7 day of acid challenge: data are expressed as medium percentage of weight loss.

\begin{tabular}{cccc}
\hline GROUPS & \multicolumn{3}{c}{ WEIGHT LOSS (\%) } \\
\cline { 2 - 4 } & 1 Day & 3 Days & 7 Days \\
\hline 1B. Voco IonoStar Plus & 0.43 & 4.45 & 9.39 \\
\hline 2B. Voco IonoStar Plus + Easy Glaze & 0.16 & 5.28 & 8.10 \\
\hline 3B. GC Equia Forte & 0.37 & 5.03 & 9.60 \\
\hline 4B. GC Equia Forte + Coat & 0.09 & 0.43 & 1.11 \\
\hline 5B. 3M ESPE Ketac Universal Aplicap & 1.40 & 4.99 & 8.33 \\
\hline 6B. GC Fuji TRIAGE CAPSULE & 2.71 & 5.33 & 7.71 \\
\hline 7B. ChemFil Rock & 1.69 & 2.15 & 2.97 \\
\hline
\end{tabular}




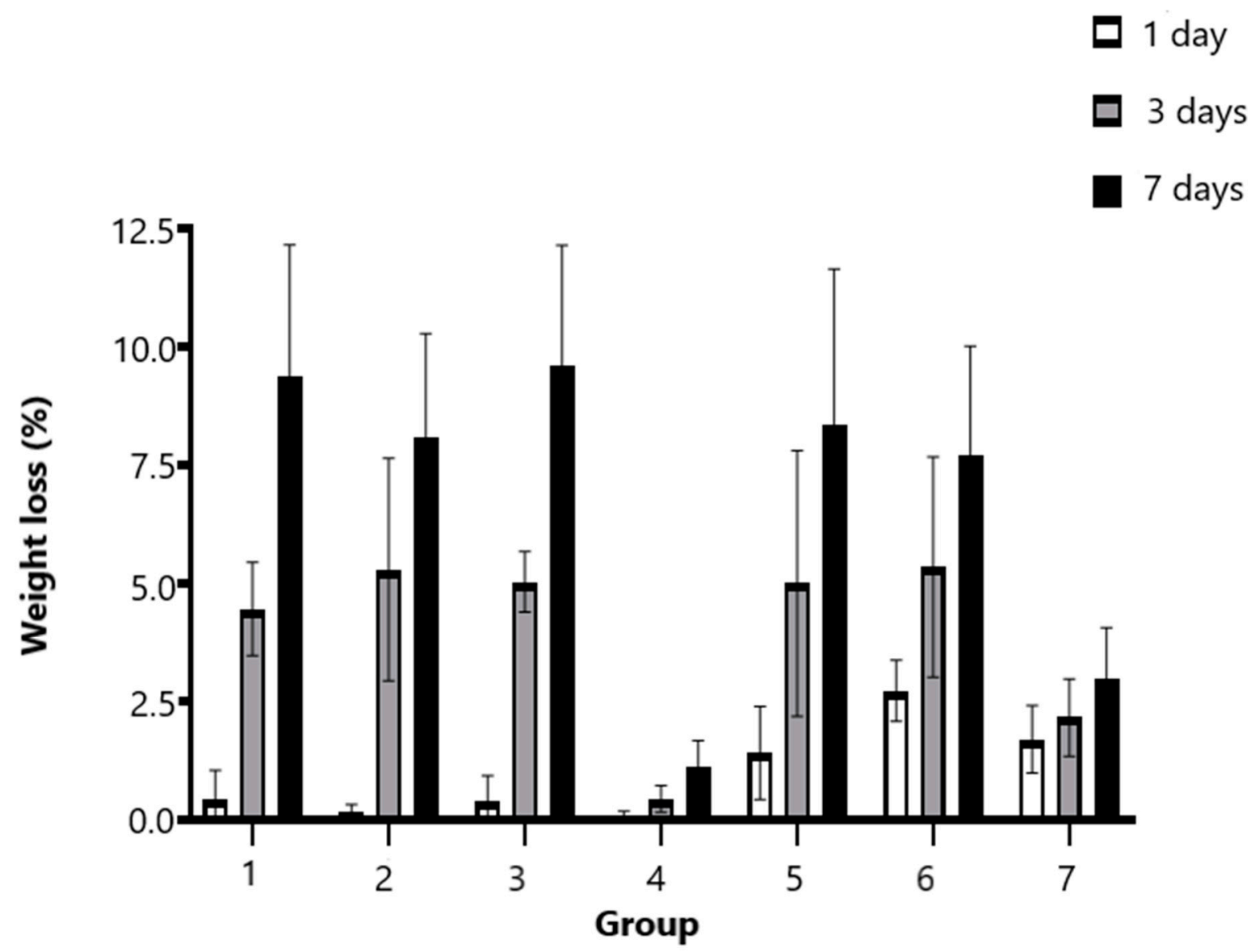

Figure 2. Glass ionomer cements: representation of weight loss after acid challenges.

\section{Discussion}

In the worldwide population, there is nowadays a large consume of artificially sweetened beverages, sport drinks, energy drinks, and other substances that cause problems to restorative dental materials [15]. Multiple studies have shown that acid substances are capable to jeopardize the microhardness and microroughness of composite resins and glass ionomers [16,17]. As in previous studies [18-20], Coca-Cola has been chosen as medium because it is the most popular acid drink and, additionally, compared to the other most popular ones available in the market, it has the lowest $\mathrm{pH}$ value, thus reporting the most significant erosive action [15]. In fact, phosphoric acid is recognized to have a more erosive action with respect to citric acid, this latter generally contained in the other soft drinks. The room temperature was chosen to reproduce the condition with which the soft drink is generally drunk.

In the present report, the behavior of seven different composite resins and seven glass-ionomer cements immersed in the abovementioned soft drink has been evaluated to assess the solubility level of these two different types of materials in acidic medium.

For the composite resins tested, the two null hypotheses considered have been accepted. No significant intragroup and intergroup differences have been assessed. In fact, the exposure of these materials to acidic challenge for 1, 3, and 7 days did not cause a significant weight loss. It is interesting to note that, among the materials tested, no significant differences resulted between flow and no flow composite resins. They both demonstrated a resistance to the weight loss caused by acidic erosion, thus confirming the evolution obtained in the last few years with these restorative materials. It is, thus, feasible to believe that acid erosion on composite resins just interfere with the superficial layer with a reduction of the surface microhardness, without interfering with the total weight of the material. 
Conversely, for the glass-ionomer cements, the two null hypotheses have been partially refused. Significant intergroup differences have been assessed for each product tested between 1, 3, and 7 days. As to intragroup differences, all glass ionomers have shown a similar weight loss from 1 to 7 days of acid challenge, with exception of GC Equia Forte + Coat (Group 4B) and ChemFil Rock (Group 7B) which showed the lowest reductions with respect to the other groups. According to these results, the loss of weight of glass ionomers immersed in acidic medium has been progressive and it has affected all the products belonging to this typology of restorative materials. The first two glass-ionomer cements tested in this study (Voco IonoStar Plus and Voco IonoStar Easy Glaze) are based on the same material, but the second product contains Easy Glaze as a protective layer which guaranteed a slight reduction of weight loss values if compared to the former product. There was instead a clear difference between Group 3B (GC Equia Forte) and 4B (GC Equia Forte + Coat): even in this case, the two groups consist of the same material, but the second product is also composed of a protective coat which has demonstrated an effective resistance and protection not only after the first day of acidic challenge but also during the subsequent time points. It is relevant to note that, in this study, GC Equia Forte showed the highest percentage of weight loss at the last evaluation $(9.60 \%)$; considering that the additional coating of this material with a protective layer reported the lowest weight loss after 7 days, this strategy could be very useful to protect glass-ionomer cements. Even Groups 5B, 6B, and 7B demonstrated a significant weight loss during the whole acid challenge, with a higher effect for 3M ESPE Ketac Universal Aplicap and GC Fuji TRIAGE CAPSULE, whereas a quite reduced one for ChemFil Rock. Comparing all the glass-ionomer cements tested in this study, GC Equia Forte + Coat (Group 4B) and ChemFil Rock (Group 7B) appeared to be the most reliable, reporting the least weight variation.

In conclusion, our study shows that all the biomimetic composite resins tested have proved to be well resistant to the acidic medium. On the other hand, some glass-ionomer cements can be subjected to an elevate and progressive loss of weight after exposure to acid beverages due to their different composition with respect to composite resins, the former based on calcium-alumino-fluoro-silicate glass and polyacrylic acid. However, if these materials are coated with a protective material this loss could decrease. Above these considerations, glass-ionomers remain among the most used materials in pediatric dentistry and orthodontics because of their action as fluoride reservoir which increases the concentration of this ion in saliva, plaque, and hard tissues of teeth, thus reducing the incidence of secondary caries [21]. Our results, thus, confirm what has been previously demonstrated in literature.

The main limitation of this report is that it has been conducted in vitro, therefore the buffering capacity of saliva, which contrasts the erosive action of acids [22], has not been considered. In addition to that, weight loss should be evaluated over a longer period (e.g., 30 days). Moreover, the specific composition of each restorative material has been regarded as the only factor influencing the severity of the changes caused by acidic solutions, conversely other in vivo factors, such as alimentary habits and oral hygiene procedures must be considered [3]. Finally, in our study, as in previous ones [23-25], no morphological evaluations were conducted to assess the variations of the materials' surfaces after acidic exposition. Accordingly, despite our results appear to be interesting from a clinical point of view, more detailed analyses should be conducted, encompassing for instance the use of SEM and AFM analysis.

\section{Conclusions}

Under the limitations of this in vitro study, we can conclude that acidic erosion does not significantly affect the weight of different biomimetic resin composites available in the market, neither considering intra- or inter-group comparisons after an acid challenge of three timepoints $(p>0.05)$. Conversely, all glass-ionomers (Groups 1B-7B) showed a significant and progressive weight loss after 1,3, and 7 days of acid exposure $(p<0.05)$ (intragroup differences). This reduction was significantly lower for GC Equia Forte + Coat 
and for ChemFil Rock, with respect to the other cements $(p<0.05)$ (intergroup differences). However, the use of glass-ionomer cements remains fundamental in orthodontics and pedodontics. In addition to that, specific recent glass-ionomers avoid this limitation by requiring the combination with a protective coat which preserves the characteristics of the bulk material.

Author Contributions: Conceptualization, C.P. and A.S.; methodology, A.S. and G.P.; software, A.S. and G.P.; validation, C.P., A.S., and G.P.; formal analysis, A.S.; investigation, G.P.; resources, M.C. (Marco Colombo) and M.C. (Marco Chiesa); data curation, A.S. and G.P.; writing—original draft preparation, A.S. and S.G.; writing—review and editing, C.P. and A.S.; visualization, A.S. and P.Z.; supervision, C.P.; project administration, C.P; funding acquisition, M.C. (Marco Colombo) and M.C. (Marco Chiesa). All authors have read and agreed to the published version of the manuscript.

Funding: This research received no external funding.

Data Availability Statement: The data presented in this study are available on request from the corresponding author.

Acknowledgments: The Authors would like to thank the Manufacturers of the products tested.

Conflicts of Interest: The authors declare no conflict of interest.

\section{References}

1. Frencken, J.E.; Sharma, P.; Stenhouse, L.; Green, D.; Laverty, D.; Dietrich, T. Global epidemiology of dental caries and severe periodontitis-A comprehensive review. J. Clin. Periodontol. 2017, 44, S94-S105. [CrossRef] [PubMed]

2. Pepla, E.; Besharat, L.K.; Palaia, G.; Tenore, G.; Migliau, G. Nano-hydroxyapatite and its applications in preventive, restorative and regenerative dentistry: A review of literature. Ann. Stomatol. 2014, 5, 108-114. [CrossRef]

3. Coelho, A.; Paula, A.; Amaro, I.; Marto, C.M.; Costa, N.; Saraiva, J.; Ferreira, M.M.; Antunes, P.; Carrilho, E. Mechanical Characterization of Two Dental Restorative Materials after Acidic Challenge. J. Compos. Sci. 2021, 5, 31. [CrossRef]

4. Yilmaz, E.; Sadeler, R. Effect of artificial aging environment and time on mechanical properties of composite materials. J. Dent. Res. Rev. 2018, 5, 111. [CrossRef]

5. Da Silva, M.A.B.; Vitti, R.P.; Sinhoreti, M.A.; Consani, R.L.; Silva-Junior, J.G.; Tonholo, J. Effect of alcoholic beverages on surface roughness and microhardness of dental composites. Dent. Mater. J. 2016, 35, 621-626. [CrossRef]

6. Toledano, M.; Osorio, R.; Osorio, E.; Fuentes, V.; Prati, C.; Garcia-Godoy, F. Sorption and solubility of resin-based restorative dental materials. J. Dent. 2003, 31, 43-50. [CrossRef]

7. Festuccia, M.S.; Garcia Lda, F.; Cruvinel, D.R.; Pires-De-Souza Fde, C. Color stability, surface roughness and microhardness of composites submitted to mouthrinsing action. J. Appl. Oral Sci. 2012, 20, 200-205. [CrossRef]

8. Briso, A.L.; Caruzo, L.P.; Guedes, A.P.; Catelan, A.; dos Santos, P.H. In vitro evaluation of surface roughness and microhardness of restorative materials submitted to erosive challenges. Oper. Dent. 2011, 36, 397-402. [CrossRef]

9. Kazak, M.; Tiryaki, M.; Turkes Basaran, E.; Gokce, B.Y. Evaluating the effects of different beverages with daily consumption habits on the wear of restorative materials. Odontology 2020, 108, 636-645. [CrossRef]

10. de Luca Cunha, C.M.B.; Wambier, L.M.; Dias, G.F.; Reis, A.; Alves, F.B.T.; Chibinsk, A.C.; Wambier, D.S. In Vitro Evaluation of the Impact of Erosive/Abrasive Challenge in Glass Ionomer Cements. Biomed. J. Sci. Tech. Res. 2017, 1, 1263-1266.

11. Perera, D.; Yu, S.C.H.; Zeng, H.; Meyers, I.A.; Walsh, L.J. Acid Resistance of Glass Ionomer Cement Restorative Materials. Bioengineering 2020, 7, 150. [CrossRef]

12. Colombo, M.; Gallo, S.; Poggio, C.; Ricaldone, V.; Arciola, C.R.; Scribante, A. New Resin-Based Bulk-Fill Composites: In vitro Evaluation of Micro-Hardness and Depth of Cure as Infection Risk Indexes. Materials 2020, 13, 1308. [CrossRef]

13. Zorzin, J.; Maier, E.; Harre, S.; Fey, T.; Belli, R.; Lohbauer, U.; Petschelt, A.; Taschner, M. Bulk-fill resin composites: Polymerization properties and extended light curing. Dent. Mater. 2015, 31, 293-301. [CrossRef]

14. Beltrami, R.; Chiesa, M.; Scribante, A.; Allegretti, J.; Poggio, C. Comparison of shear bond strength of universal adhesives on etched and nonetched enamel. J. Appl. Biomater. Funct. Mater. 2016, 14, e78-e83. [CrossRef] [PubMed]

15. da Silva, M.A.; Vitti, R.P.; Sinhoreti, M.A.; Consani, R.L.; Júnior, J.G.; Tonholo, J. Evaluation of the Surface Roughness and Microleakage of Dental Composites Exposed to Different Beverages. J. Contemp. Dent. Pract. 2015, 16, 800-804. [PubMed]

16. Scribante, A.; Gallo, S.; Scarantino, S.; Dagna, A.; Poggio, C.; Colombo, M. Exposure of Biomimetic Composite Materials to Acidic Challenges: Influence on Flexural Resistance and Elastic Modulus. Biomimetics 2020, 5, 56. [CrossRef] [PubMed]

17. Gömeç, Y.; Dorter, C.; Ersev, H.; Guray Efes, B.; Yildiz, E. Effects of dietary acids on surface microhardness of various tooth-colored restoratives. Dent. Mater. J. 2004, 23, 429-435. [CrossRef]

18. Scribante, A.; Bollardi, M.; Chiesa, M.; Poggio, C.; Colombo, M. Flexural Properties and Elastic Modulus of Different Esthetic Restorative Materials: Evaluation after Exposure to Acidic Drink. Biomed Res. Int. 2019, 2019, 5109481. [CrossRef] 
19. Meurman, J.H.; Frank, R.M. Scanning electron microscopic study of the effect of salivary pellicle on enamel erosion. Caries Res. 1991, 25, 1-6. [CrossRef]

20. Yuan, M.; Zhang, Q.; Gao, X.J. Influence of Coca-Cola on early erosion and surface microhardness of human enamel: An in situ study. Zhonghua Kou Qiang Yi Xue Za Zhi 2016, 51, 357-361.

21. de Moraes, M.D.; de Melo, M.A.; Bezerra Dda, S.; Costa, L.S.; Saboía Vde, P.; Rodrigues, L.K. Clinical study of the caries-preventive effect of resin-modified glass ionomer restorations: Aging versus the influence of fluoride dentifrice. J. Investig. Clin. Dent. 2016, 7, 180-186. [CrossRef] [PubMed]

22. Buzalaf, M.A.; Hannas, A.R.; Kato, M.T. Saliva and dental erosion. J. Appl. Oral Sci. 2012, 20, 493-502. [CrossRef] [PubMed]

23. Xavier, A.M.; Sunny, S.M.; Rai, K.; Hegde, A.M. Repeated exposure of acidic beverages on esthetic restorative materials: An in-vitro surface microhardness study. J. Clin. Exp. Dent. 2016, 8, e312-e317. [CrossRef] [PubMed]

24. Fatima, N.; Abidi, S.Y.; Qazi, F.U.; Jat, S.A. Effect of different tetra pack juices on microhardness of direct tooth colored-restorative materials. Saudi Dent. J. 2013, 25, 29-32. [CrossRef] [PubMed]

25. Szalewski, L.; Wójcik, D.; Bogucki, M.; Szkutnik, J.; Różyło-Kalinowska, I. The Influence of Popular Beverages on Mechanical Properties of Composite Resins. Materials 2021, 14, 3097. [CrossRef] [PubMed] 